\title{
The lack of association between bacille Calmette-Guérin vaccination and clustering of Aboriginals with tuberculosis in western Canada
}

\author{
Victoria J Cook MD FRCPC ${ }^{1,2}$, Eduardo Hernández-Garduño MD MHSc ${ }^{1}$, Dennis Kunimoto MD FRCPC ${ }^{3}$, \\ Earl S Hershfield MD FRCPC ${ }^{4}$, E Anne Fanning MD FRCPC ${ }^{3}$, Vernon H Hoeppner MD FRCPC ${ }^{5}$, \\ R Kevin Elwood MB MRCPI FRCPC ${ }^{1,2}$, J Mark FitzGerald MB MRCPI FRCPC ${ }^{2,6}$, \\ and the Canadian Molecular Epidemiology of Tuberculosis Study Group
}

\begin{abstract}
VJ Cook, E Hernández-Garduño, D Kunimoto, et al; Canadian Molecular Epidemiology of Tuberculosis Study Group. The lack of association between bacille Calmette-Guérin vaccination and clustering of Aboriginals with tuberculosis in western Canada. Can Respir J 2005;12(3):134-138.
\end{abstract}

BACKGROUND: Tuberculosis (TB) remains a major health problem for Aboriginal people in Canada, with high rates of clustering of active TB cases. Bacille Calmette-Guérin (BCG) vaccination has been used as a preventive measure against TB in this high-risk population.

OBJECTIVES: The study was designed to determine if BCG vaccination in Aboriginal people influenced recent TB transmission through an analysis of the clustering of TB cases.

METHODS: A retrospective analysis of all culture-positive Mycobacterium tuberculosis cases in Aboriginal people in western Canada (1995 to 1997) was performed. Isolates were analyzed using standard methodology for restriction fragment length polymorphism and spoligotyping.

RESULTS: Of 256 culture-positive Aboriginal TB cases, BCG status was confirmed in 216 (84\%) cases; $34 \%$ had been vaccinated with BCG, $57 \%$ were male and $56 \%$ were living on-reserve. Patients who had been vaccinated with BCG were younger than unvaccinated individuals (mean age $32.4 \pm 1.65$ years versus $45.0 \pm 1.8$ years, $\mathrm{P}<0.0001$ ). Clustering was found in $62 \%$ of cases: $59 \%$ of non-BCG vaccinated cases were clustered versus $68 \%$ of those vaccinated with BCG $(P=0.16)$. Younger patients (younger than 60 years of age) were more likely to be clustered in the univariate analysis $(\mathrm{P}<0.01)$. When age, sex, province, and HIV and reserve status were controlled for, $\mathrm{BCG}$ vaccination was not associated with clustering (OR 1.3, 95\% CI 0.7 to 2.6).

CONCLUSIONS: BCG vaccinated Aboriginal people were no less likely to have active TB from recently transmitted disease. BCG vaccination appears to have limited value in preventing clustering of TB cases within this high-risk community.

\section{Absence de lien entre le vaccin BCG et les cas de tuberculose chez des Autochtones de l'Ouest canadien}

HISTORIQUE : La tuberculose (TB) reste un important problème de
santé publique chez les Premières nations du Canada, avec des taux élevés
de TB active. Le vaccin BCG (bacille de Calmette-Guérin) a été utilisé
comme mesure préventive contre la TB auprès de cette population à haut
risque. OBJECTIF : L'étude a été conçue afin de déterminer par le biais d'une analyse typologique des cas de TB quel a été l'effet d'un vaccin BCG sur les Premières nations lors d'une propagation récente de la maladie.

MÉTHODES : Analyse rétrospective de tous les cas de Mycobaterium tuberculosis positifs à la culture chez les Premières nations de l'Ouest canadien (1995 à 1997). Les isolats ont été analysés à l'aide d'une méthodologie standard de polymorphisme de restriction et de spoligotypage.

RÉSULTATS : Parmi 256 cas de TB positifs à la culture chez les Autochtones, le statut à l'égard du BCG a été confirmé dans 216 cas (84 \%); $34 \%$ avaient reçu un vaccin BCG, $57 \%$ étaient des hommes et $56 \%$ vivaient sur une réserve. Les patients qui avaient été vaccinés avec le BCG étaient plus jeunes que les individus non vaccinés (âge moyen 32,4 $\pm 1,65$ ans vs 45,0 $\pm 1,8$ ans; $\mathrm{P}<0,0001)$. Des concentrations de cas ont été retrouvées dans une proportion de $62 \%$ : 59 \% des cas non vaccinés par le BCG ont été comparés aux $68 \%$ des sujets vaccinés $(\mathrm{P}=0,16)$. Les patients plus jeunes (de moins de 60 ans) étaient plus susceptibles de faire partie des concentrations de cas lors de l'analyse univariée $(\mathrm{P}<0,01)$. Lorsque l'on tenait compte de l'âge, du sexe, de la province de résidence, du VIH et du fait de vivre ou non sur une réserve, le vaccin BCG n'a été associé à aucune concentration de cas (RR 1,3; IC $95 \%, 0,7$ à 2,6).

CONCLUSIONS : Les personnes autochtones vaccinées par le BCG n'étaient pas moins susceptibles de souffrir d'une TB active récemment transmise. Le BCG semble avoir une utilité limitée pour ce qui est de prévenir la TB au sein de cette communauté à haut risque.

Key Words: BCG vaccination; Clustering; Molecular epidemiology; Tuberculosis

$\mathrm{T}$ uberculosis (TB) remains a major public health problem for Aboriginal people in Canada (1). Although rates of TB in Aboriginal Canadians continue to fall, the incidence of TB is still more than 10 to 15 times that of the non-Aboriginal Canadian population (2). The principal means of controlling $\mathrm{TB}$ in Aboriginal communities follow national guidelines:

finding active cases and the early initiation of treatment, complete contact investigation and treatment of latent infection, and appropriate infection control measures (3). Bacille Calmette-Guérin (BCG) vaccination has been recommended as an effective preventive measure in this high-risk population for over 40 years $(4-6)$.

${ }^{1}$ Division of TB Control, British Columbia Centre for Disease Control; ${ }^{2}$ Department of Medicine, University of British Columbia, Vancouver,

British Columbia; ${ }^{3}$ Department of Medicine, University of Alberta, Edmonton, Alberta; ${ }^{4}$ Department of Medicine, University of Manitoba,

Winnipeg, Manitoba; ${ }^{5}$ Department of Medicine, University of Saskatchewan, Saskatoon, Saskatchewan; ${ }^{6}$ Center for Clinical Epidemiology and Evaluation, Vancouver General Hospital, Vancouver, British Columbia

Correspondence: Dr Victoria J Cook, Division of TB Control, British Columbia Centre for Disease Control, 655 West 12th Avenue, Vancouver,

British Columbia V5Z 4R4. Telephone 604-660-6127, fax 604-660-1950, e-mail victoria.cook@bccdc.ca 
At present, $B C G$ vaccination in Canada is offered to specific high-risk communities, primarily Aboriginal newborns living on-reserve (3). However, the role of BCG vaccination in Canada remains controversial and under review due to questions of efficacy and side effects, which vary from local adverse reactions to disseminated BCG infection (7-12). If it is assumed that BCG vaccination has a protective effect against $\mathrm{TB}$, it is reasonable to suspect that there may be an influence on recent TB transmission in a BCG-vaccinated population because of a reduced chance of disease acquisition.

Molecular epidemiology techniques provide a surrogate marker for recent transmission. TB isolates from culture-positive cases can be fingerprinted using restriction fragment length polymorphism (RFLP) to assess the relatedness. Clustered strains with identical fingerprint patterns suggest recent or ongoing transmission within a community, while unique strains suggest reactivation of the disease or acquisition elsewhere $(13,14)$. The proportion of clustering or recent transmission within Aboriginal communities has been estimated to be $50 \%$ to $60 \%$ from previous studies $(14,15)$. The objective of the present study was to determine if $\mathrm{BCG}$ vaccination in Aboriginal people from western Canada influenced TB transmission through an analysis of the proportion of TB cases that were clustered.

\section{METHODS}

\section{Study design}

The present study involved the analysis of data collected prospectively for the Canadian Molecular Epidemiology of Tuberculosis Study Group, an evaluation of all Mycobacterium tuberculosis-positive cultures in western Canada over a two-year period from February 1, 1995, to January 31, 1997 (14). Isolates from British Columbia, Alberta, Saskatchewan, Manitoba and a small Aboriginal community in northwestern Ontario (TB control coordinated through Manitoba) were included in the study. A descriptive analysis was performed on the demographic and clinical data on each case, as well as the laboratory evaluation of isolates using standardized molecular techniques to assess recent transmission by clustering.

\section{Patients}

All cases of M tuberculosis culture-positive TB in Aboriginal people, on- and off-reserve, were included for analysis. The term Aboriginal is a collective name used to describe the indigenous peoples of North America and their descendants. Aboriginal Canadians include status and nonstatus First Nations people (previously known as Indian), Inuit (of Arctic Canada) and Métis (mixed First Nations and European heritage) as reported by the First Nations and Inuit Health Branch of Canada. Status First Nations people are registered with and recognized by the Canadian government, while nonstatus First Nations people are those who consider themselves members of a First Nation without official recognition by the Canadian government. A reserve has been defined as a tract of land set apart for use and benefit by Aboriginal people. Canadian-born/non-Aboriginal persons who do not routinely receive BCG vaccination and the foreign-born in whom a documented BCG vaccination history is often difficult to confirm were excluded.

\section{Laboratory evaluation}

Mycobacterium species were identified using conventional biochemical testing and RNA hybridization probes (16). In western Canada, all cultures for $\mathrm{M}$ tuberculosis are carried out in provincial reference laboratories. All positive cultures were sent to the study laboratory in Edmonton, Alberta, for analysis using molecular epidemiology techniques. Isolates were analyzed using standard methodology and RFLP fingerprinting (described in detail elsewhere $[14,15,17])$. Spoligotyping (a secondary typing system) was used to discriminate between strains of $M$ tuberculosis with less than six bands (copies) of the IS6110 genotype sequence (18). Standard methods were used to exclude false positive results from laboratory cross-contamination (19). A cluster was defined as two or more isolates within the study group with an identical RFLP fingerprint (regardless of province of diagnosis), while nonclustered cases had a unique RFLP fingerprint. All cases enrolled in the present study were culture-positive and had DNA fingerprinting completed.

\section{Epidemiology evaluation}

Intradermal BCG vaccination (Connaught attenuated substrain of Mycobacterium bovis BCG; Aventis Pasteur, Canada) is provided, on a voluntary basis, to Aboriginal newborns living on-reserve through the First Nations and Inuit Health Branch of Health Canada (3). The strain and manufacturer of the BCG vaccine was the same for all provinces. Although BCG vaccination is a government policy, coverage is variable because it is left to the discretion of the individual and health care worker. Coverage varies by province and although participation is waning, approximately $50 \%$ of all eligible Aboriginal persons have received the vaccine (20). All provinces involved in the study have centralized TB registries where BCG vaccination history is documented. Each registry was contacted for the collection of epidemiological data, including demographic and clinical information for all Aboriginal cases of TB. Demographic information included age at diagnosis, sex and province where the diagnosis was made. Clinical information included history of BCG (yes or no) and HIV infection status. Complete information was collected on predesigned standardized data collection sheets and then entered onto a computer spreadsheet for data analysis.

\section{Statistical analysis}

Descriptive statistics of demographic and clinical characteristics were computed using the SAS statistical package (version 8.0, SAS Inc, USA). Associations were evaluated by Student's $t$ test, $\chi^{2}$ and multivariate logistic regression.

\section{RESULTS}

During the study period, a total of 944 cases of bacteriologically proven active TB (M tuberculosis) were diagnosed in the four provinces involved in the study. Among Aboriginal people, a total of 256 cases of culture-positive TB in western Canada from February 1, 1995, to January 31, 1997, were identified. Of these 256 cases, BCG status was confirmed in 216 of the total cases (84\%). This involved contacting each provincial TB program registry to review TB control and clinical records for formal BCG vaccination information. The $16 \%$ of culture-positive Aboriginal TB cases that did not have documentation of BCG status were, therefore, excluded from the analysis. The remaining 216 cases that were analyzed as the study group had confirmed positive or negative BCG vaccination status based on formal documentation for all provinces.

A history of BCG vaccination was documented in 73 (34\%) patients (Table 1). Of all cases, $57 \%$ were male and $56 \%$ were living on-reserve at the time of their TB diagnosis. Patients with a positive history of BCG vaccination were younger than those with a negative history (mean age $32.4 \pm 1.65$ years versus $45.0 \pm 1.8$ years, respectively; $\mathrm{P}<0.0001)$. 
TABLE 1

Patient demographics: No bacille Calmette-Guérin (BCG) vaccination versus $B C G$ vaccination, $n(\%)$

\begin{tabular}{|c|c|c|c|c|}
\hline & $\begin{array}{c}\text { No BCG, } \\
n=143(66)\end{array}$ & $\begin{array}{c}\text { BCG, } \\
n=73(34)\end{array}$ & $\begin{array}{c}\text { Total, } \\
\mathrm{n}=216(100)\end{array}$ & $\mathbf{P}^{*}$ \\
\hline \multicolumn{5}{|l|}{$\operatorname{Sex}^{\dagger}$} \\
\hline Male & $81(66)$ & $41(34)$ & $122(100)$ & \multirow[t]{2}{*}{0.92} \\
\hline Female & $61(67)$ & $30(33)$ & $91(100)$ & \\
\hline \multicolumn{5}{|c|}{ Age at diagnosis (years) } \\
\hline $0-25$ & $31(62)$ & $19(38)$ & $50(100)$ & \multirow[t]{3}{*}{0.0007} \\
\hline $26-60$ & $76(60)$ & $51(40)$ & $127(100)$ & \\
\hline $60+$ & $36(92)$ & $3(8)$ & $39(100)$ & \\
\hline \multicolumn{5}{|c|}{ Province of diagnosis } \\
\hline Province A & $40(77)$ & $12(23)$ & $52(100)$ & \multirow[t]{4}{*}{0.35} \\
\hline Province B & $12(57)$ & $9(43)$ & $21(100)$ & \\
\hline Province C & $33(65)$ & $18(35)$ & $51(100)$ & \\
\hline Province D & $58(63)$ & $34(37)$ & $92(100)$ & \\
\hline \multicolumn{5}{|l|}{ Reserve status } \\
\hline On-reserve & $75(63)$ & $45(37)$ & $120(100)$ & 0.19 \\
\hline Clustered cases & $84(63)$ & $50(37)$ & $134(100)$ & 0.16 \\
\hline
\end{tabular}

*Using $\chi^{2}$ analysis; ${ }^{\dagger}$ Sex total is $n=213$ because three missing values were not available from the database

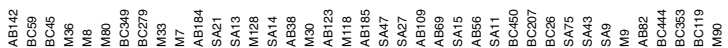

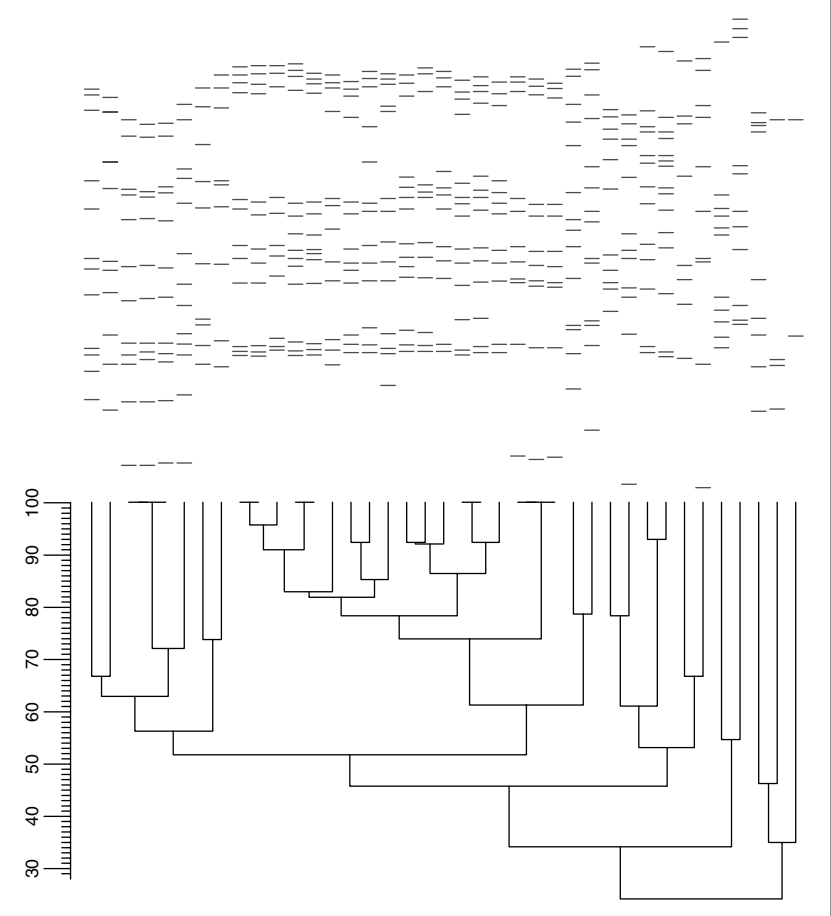

Figure 1) A representative sample (randomly selected) of Aboriginal isolate DNA fingerprints

Of the 216 culture-positive cases of TB in Aboriginal Canadians, only 12 isolates had fewer than six bands (low-copy) and went onto spoligotyping. Clustering was found in $62 \%$ of cases of culture-positive TB in Aboriginal Canadians (Table 1 and Figure 1). Of the 12 low-copy strains, five (42\%) were clustered by spoligotyping compared with $63 \%$ of the high-copy strains clustered by RFLP ( $\mathrm{P}=0.13)$. Clustering occurred in $59 \%$
TABLE 2

Multivariate analysis of clustering of Aboriginal tuberculosis cases*

\begin{tabular}{llc}
\hline & OR & $\mathbf{9 5 \%} \mathbf{C l}$ \\
\hline Age $<25$ years & 2.7 & 0.9 to 7.1 \\
Age 26 to 60 years & 2.1 & 0.9 to 4.8 \\
Female sex & 0.5 & 0.3 to 0.9 \\
BCG vaccination & 1.3 & 0.7 to 2.6 \\
HIV-positive & 1.4 & 0.4 to 4.7 \\
Off-reserve & 1.3 & 0.7 to 2.5 \\
Province A & 0.2 & 0.1 to 0.6 \\
Province B & 0.1 & 0.03 to 0.3 \\
Province D & 0.3 & 0.1 to 0.8
\end{tabular}

${ }^{*}$ Reference groups older than 60 years, Province $C$ (elderly defined as older than 60 years). BCG Bacille Calmette-Guérin

TABLE 3

Province of diagnosis and clustering of tuberculosis cases, $\mathbf{n}(\%)$

\begin{tabular}{lcccl}
\hline & $\begin{array}{c}\text { Clustered } \\
\mathbf{n = 1 3 4 ( 6 2 )}\end{array}$ & $\begin{array}{c}\text { Nonclustered } \\
\mathbf{n = 8 2 ( 3 8 )}\end{array}$ & $\begin{array}{c}\text { Total } \\
\mathbf{n = 2 1 6 ( 1 0 0 )}\end{array}$ & \multicolumn{1}{c}{$\mathbf{P}^{*}$} \\
\hline Province A & $29(56)$ & $23(44)$ & $52(100)$ & 0.29 \\
Province B & $8(38)$ & $13(62)$ & $21(100)$ & 0.02 \\
Province C & $42(82)$ & $9(18)$ & $51(100)$ & 0.0006 \\
Province D & $55(60)$ & $37(40)$ & $92(100)$ & 0.56 \\
\hline
\end{tabular}

${ }^{*} U$ sing $\chi^{2}$ analysis; each province is compared with all other provinces combined

of non-BCG cases compared with $68 \%$ of BCG cases, and this difference was not statistically significant $(\mathrm{P}=0.16)$. Age was found to be the most significant predictor for clustering in the univariate analysis because younger patients were more likely to be clustered $(\mathrm{P}<0.01)$. After controlling for age, sex, province, and HIV and reserve status, BCG vaccination was not associated with clustering by logistic regression (OR 1.3, 95\% CI 0.7 to 2.6) (Table 2).

No significant difference was observed in BCG vaccination status among the provinces despite the variable coverage (Table 1), although the province of diagnosis appeared to influence clustering (Table 3). Province B had the lowest proportion of clustered cases (38\%), while Province C had the highest proportion of clustered cases (82\%). When looking at BCG-vaccinated patients alone $(n=73)$, no relationship was observed between the province of diagnosis and clustering (data not shown). It was also determined that BCG vaccination was not associated with cluster size or whether the patient was considered to be the source case of the cluster or secondary case by date of diagnosis (data not shown).

A subgroup analysis was performed on the cases of HIV/TB coinfection in the study population. Clustering was found in $69 \%$ of these cases ( 11 of 16 cases): $58 \%$ of non-BCG (seven of 12 cases) versus $100 \%$ of BCG cases (four of four cases) ( $\mathrm{P}=0.17$, Fisher's exact test). HIV status was not associated with clustering in the multivariate analysis (OR 1.4, 95\% CI 0.4 to 4.7, Table 2)

\section{DISCUSSION}

The role of BCG vaccination in Canada remains controversial, although it is generally agreed that vaccination in infancy provides protection against the most severe forms of $\mathrm{TB}$ $(8,9,21)$. Although the more severe and reportable adverse 
reactions to BCG vaccination remain uncommon, disseminated BCG infection and death in patients with previously unrecognized congenital and acquired immune deficiencies have been reported $(11,12)$. The reduction in TB incidence and the concern regarding $\mathrm{BCG}$-associated deaths has fuelled the debate on BCG vaccination in Canada.

The present study was designed to assess the influence of BCG vaccination on the clustering of $\mathrm{TB}$ cases in the Aboriginal communities of western Canada. The administration of BCG to an unvaccinated individual is thought to enhance cell-mediated immunity in the face of subsequent exposure to the tubercle bacillus. Rapid mobilization of host immunity to prevent dissemination is understood to be the mechanism that reduces the risk of miliary and meningeal TB, an effect of great clinical significance in the pediatric population. The BCG vaccine's ability to prevent TB infection in an older population is less efficacious but may limit the progression of infection to disease in approximately $50 \%$ of those vaccinated $(8,9)$. If the $\mathrm{BCG}$ vaccine can influence the development of disease at the time of initial infection, it would be reasonable to assume that a BCG-vaccinated person would less likely be involved in active transmission due to their intrinsic reduced chance for disease. Therefore, a BCG-vaccinated person would less likely be involved in a clustering of TB cases as a marker of ongoing disease transmission. However, this association was not found in our study population. BCGvaccinated Aboriginal people were no less likely to have active TB from recently transmitted disease than were unvaccinated individuals.

Aboriginal communities are an important population in which to study TB transmission because the incidence of TB is much higher than the Canadian average, and in recent studies $(14,15)$, being an Aboriginal person was a strong predictor of clustering of TB cases. These results, as well as the present study's reported rate of clustering (63\%), confirm ongoing transmission in Aboriginal communities (Table 1). Explanations for the higher incidence of TB among Aboriginal communities have included the remoteness of communities, health worker shortages, housing and socioeconomic conditions, substance abuse, the prevalence of latent TB infection and, more recently, the impact of HIV coinfection $(1,20,22,23)$.

The investigation of DNA fingerprints in western Canada has confirmed the heterogeneity of clusters across ethnic and provincial boundaries (14). In the present study, only $24 \%$ (32 of 134) of Aboriginal persons were clustered with other Aboriginal persons only (data not shown). This genotypic diversity is especially relevant to Aboriginal persons, the focus of the present study, in that a unique strain may be interpreted as endemic, leading to the potential overestimation of clustering. Studies $(24,25)$ have suggested that large clusters of TB cases may represent historic transmission of an endemic or unique strain in both Aboriginal and non-Aboriginal Canadian populations. The identification of mixed clusters in the present study confirms that clustering within the Aboriginal communities of western Canada is not solely driven by unique strains within this ethnic group. The concurrent use of multiple genotyping methods, including mycobacterial interspersed repetitive units, has been suggested to provide a more conservative estimate of clustering (25).

We determined that younger patients were more likely to be in a cluster (Table 2). Young people are an important population in which to assess the impact of BCG vaccination on
TB transmission because BCG vaccination does not provide absolute or permanent protection into adulthood. If given in infancy, the protective effect of BCG vaccination may, at best, last 15 to 20 years postinoculation, although there is no agreement on the duration of immunity and efficacy (26-28). While clustering is more common in the young, older patients can develop active disease from reactivation of a latent infection and then become a potential source of disease transmission $(13-15)$. Due to the time-sensitive efficacy of BCG vaccination, it may not have been reasonable to expect vaccination status to influence the rates of clustering found in older Aboriginal people in the present study.

The current study established that younger Aboriginals were more likely to be involved in clusters irrespective of BCG status. Even when controlling for age, sex, province, and HIV and reserve status, there was no significant difference in clustering based on BCG vaccination status. When patients younger than 26 years of age were analyzed, in whom BCG vaccination might be expected to have the strongest influence, we found no significant difference with respect to BCG vaccination status and clustering (data not shown). We also examined the possibility that BCG vaccination influenced the number of large cluster outbreaks, although we found no association between BCG vaccination status and the size of clusters. Although BCG vaccination might provide some protection against the development of $\mathrm{TB}$, there does not appear to be any influence on recent TB transmission through cluster analysis within this Aboriginal cohort.

During the study period, the incidence of TB in Aboriginals varied by province based on population statistics from Health Canada (2). Although the proportion of clustered cases varied by region, with the majority of clustering occurring in the provinces with the highest incidences, the extent of BCG coverage did not appear to have any influence on TB transmission in the present cohort. It should be noted that Province $\mathrm{C}$, with the highest incidence of TB and the highest rate of clustering in the current study, has had one of the highest burdens of TB disease in Canada for the past decade. In 2001 alone, the incidence of TB in Aboriginals in Province $\mathrm{C}$ was more than three times the incidence of all Aboriginals in Canada (2). A subanalysis of Aboriginal TB cases in Province $\mathrm{C}$ showed no association between clustering and BCG vaccination (data not shown).

HIV infection is a well-documented risk factor for the development of TB and the clustering of cases (29). While the official rate of HIV/TB coinfection in Canada is not yet available, the impact of HIV on TB transmission and clustering during our study period was likely minimal due to the low prevalence of coinfection (29). In those patients with confirmed HIV/TB coinfection $(n=16)$, we were unable to detect a difference in clustering by BCG vaccination which might have been expected given the potential for significant immune suppression. One could argue that any effect of BCG vaccination would be lost in HIV-positive patients that are severely immune compromised. However, with HIV-positive patients excluded from the analysis, we were still unable to find a difference with respect to BCG vaccination status and clustering. It remains inherently difficult to assess the contribution of HIV infection to the high rate of clustering in the present study population. Given the increased risk of HIV infection among high-risk Aboriginal communities, it is possible that the potential impact of HIV on TB transmission in this community has yet to be determined (22). 
Cluster outbreaks are a major challenge confronting all TB control programs. Aboriginal people who received BCG vaccination were no less likely to have active TB from recently transmitted disease. Therefore, BCG vaccination seems to have limited value in preventing the clustering of TB cases within this high TB prevalence community. The lack of influence of BCG vaccination on clustering in Aboriginal communities supports the belief that more appropriate strategies may be required to control TB transmission in this high-risk community.

ACKNOWLEDGEMENTS: Canadian Molecular Epidemiology of Tuberculosis Working Group: Vancouver: Drs JM FitzGerald, RK Elwood, WA Black, A Donald, M Rodriguez; Edmonton: Drs D Kunimoto, A Fanning, J Talbot; Saskatchewan: Drs V Hoeppner, T Martin; Manitoba: Dr ES Hershfield.

FUNDING: Dr FitzGerald is a recipient of a Vancouver General Hospital Scientist Award, a Michael Smith Distinguished Scholar award and a British Columbia Lung Canadian Institutes of Health Research Investigator. The study was funded, in part, by the British Columbia Lung Association and Health Canada.

\section{REFERENCES}

1. FitzGerald JM, Wang L, Elwood RK. Tuberculosis: 13. Control of the disease among aboriginal people in Canada. CMAJ 2000;162:351-5.

2. Tuberculosis in Canada; Annual TB Control Reports, 1996 to 2001. $<$ http://www.phac-aspc.gc.ca/publications_2_e.html> (Version current at November 10, 2004).

3. Canadian Thoracic Society, Standards Committee (Tuberculosis). Canadian Tuberculosis Standards, 5th edn. Ottawa: Canadian Lung Association, 2000.

4. Ferguson RG and Sime AB. BCG vaccination of Indian infants in Saskatchewan. Tubercle 1949;30:5-11.

5. Young TK, Hershfield ES. A case-control study to evaluate the effectiveness of mass neonatal BCG vaccination among Canadian Indians. Am J Public Health 1986;76:783-6.

6. Houston S, Fanning A, Soskolne CL, Fraser N. The effectiveness of bacillus Calmette-Guerin (BCG) vaccination against tuberculosis. A case-control study in Treaty Indians, Alberta, Canada. Am J Epidemiol 1990;131:340-8.

7. Clemens JD, Chuong JJ, Feinstein AR. The BCG controversy: A methodological and statistical reappraisal. JAMA 1983;249:2362-9.

8. Colditz GA, Brewer TF, Berkey CS, et al. Efficacy of BCG vaccine in the prevention of tuberculosis. Meta-analysis of the published literature. JAMA 1994;271:698-702.

9. Colditz GA, Berkey CS, Mosteller F, et al. The efficacy of bacille Calmette-Guerin vaccination of newborns and infants in the prevention of tuberculosis: Meta-analyses of the published literature. Pediatrics 1995;96:29-35.

10. Brewer TF, Colditz GA. Relationship between bacille CalmetteGuerin (BCG) strains and the efficacy of BCG vaccine in the prevention of tuberculosis. Clin Infect Dis 1995;20:126-35.

11. FitzGerald JM. Management of adverse reactions to bacille CalmetteGuerin vaccine. Clin Infect Dis 2000;31(Suppl 3):S75-6.
12. Scheifele D, Law B, Jadavji T. Disseminated bacille CalmetteGuerin infection: Three recent Canadian cases. IMPACT. Immunization Monitoring Program, Active. Can Commun Dis Rep 1998;24:69-72,73-5.

13. Burgos MV, Pym AS. Molecular epidemiology of tuberculosis. Eur Respir J 2002;20(Suppl 36):54s-65s.

14. FitzGerald JM, Fanning A, Hoepnner V, Hershfield E, Kunimoto D; Canadian Molecular Epidemiology of TB Study Group. The molecular epidemiology of tuberculosis in western Canada. Int J Tuberc Lung Dis 2003;7:132-8.

15. Hernandez-Garduno E, Kunimoto D, Wang L, et al. Predictors of clustering of tuberculosis in Greater Vancouver: A molecular epidemiologic study. CMAJ 2002;167:349-52.

16. Kent PT, Kubica GP. Public Health Mycobacteriology: A Guide for the Level III Laboratory. Atlanta: Centers for Disease Control and Prevention, 1985.

17. van Embden JD, Cave MD, Crawford JT, et al. Strain identification of Mycobacterium tuberculosis by DNA fingerprinting: Recommendations for a standardized methodology. J Clin Microbiol 1993;31:406-9.

18. Warren RM, Streicher EM, Charalambous S, et al. Use of spoligotyping for accurate classification of recurrent tuberculosis. J Clin Microbiol 2002;40:3851-3.

19. Small PM, McClenny NB, Singh SP, Schoolnik GK, Tompkins LS, Mickelsen PA. Molecular strain typing of Mycobacterium tuberculosis to confirm cross-contamination in the mycobacteriology laboratory and modification of procedures to minimize occurrence of falsepositive cultures. J Clin Microbiol 1993;31:1677-82.

20. Clark M. Tuberculosis in First Nations Communities, 1999. Ottawa: Health Canada, 1999. <http://www.hc-sc.gc.ca/fnihb-dgspni/ fnihb/phcph/tuberculosis/publications/tuberculosis_fnc.pdf> (Version current at November 11, 2004).

21. The role of BCG vaccine in the prevention and control of tuberculosis in the United States. A joint statement by the Advisory Council for the Elimination of Tuberculosis and the Advisory Committee on Immunization Practices. MMWR Recomm Rep 1996;45:1-18

22. Craib KJ, Spittal PM, Wood E, et al. Risk factors for elevated HIV incidence among Aboriginal injection drug users in Vancouver. CMAJ 2003;168:19-24.

23. Wang L, Noertjojo K, Elwood RK, et al. Tuberculosis among aboriginal and non-aboriginal persons in British Columbia. Can Respir J 2000;7:151-7.

24. Nguyen D, Brassard P, Westley J, et al. Widespread pyrazinamideresistant Mycobacterium tuberculosis family in a low-incidence setting. J Clin Microbiol 2003;41:2878-83.

25. Nguyen D, Proulx JF, Westley J, Thibert L, Dery S, Behr MA. Tuberculosis in the Inuit community of Quebec, Canada. Am J Respir Crit Care Med 2003;168:1353-7.

26. Sterne JA, Rodrigues LC, Guedes IN. Does the efficacy of BCG decline with time since vaccination? Int J Tuberc Lung Dis 1997;2:200-7.

27. Wilson ME, Fineberg HV, Colditz GA. Geographic latitude and the efficacy of bacille Calmette-Guerin vaccine. Clin Infect Dis 1995;20:982-91.

28. Fine PEM. Variation in protection by BCG: Implications of and for heterologous immunity. Lancet 1995;346:1339-45. (Erratum in Lancet 1996;347:340).

29. Blenkush MF, Korzeniewska-Kozela M, Elwood RK, Black W, FitzGerald JM. HIV-related tuberculosis in British Columbia: Indications of a rise in prevalence and a change in risk groups. Clin Invest Med 1996;19:271-8. 


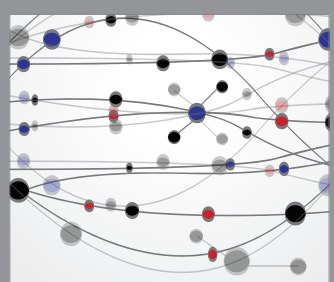

The Scientific World Journal
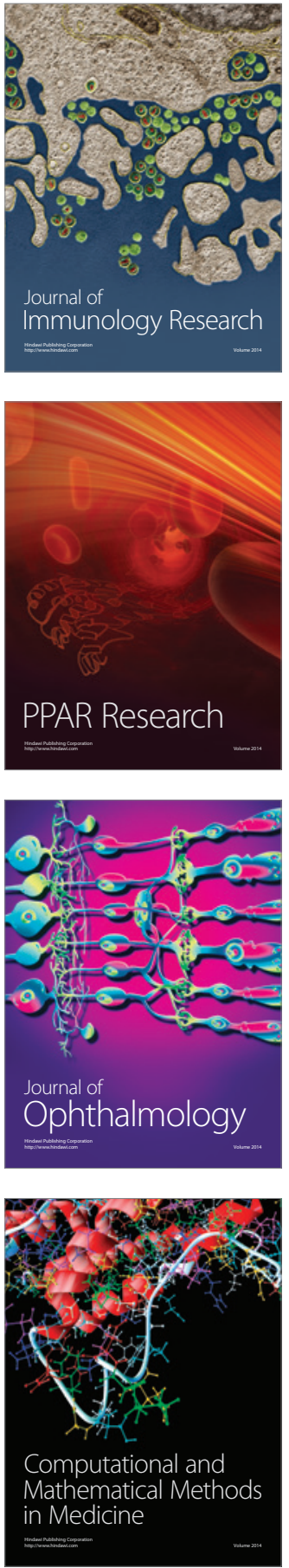

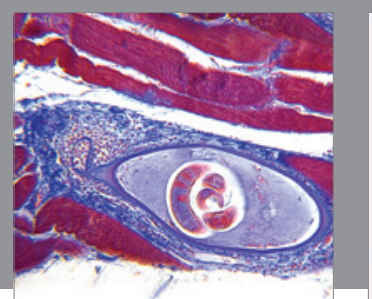

Gastroenterology Research and Practice

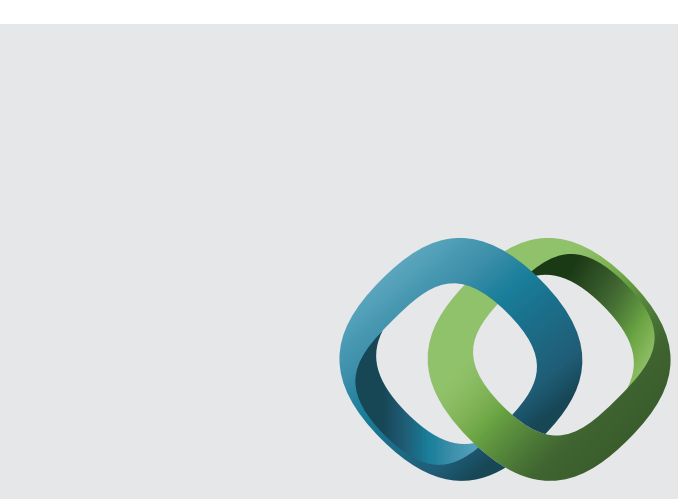

\section{Hindawi}

Submit your manuscripts at

http://www.hindawi.com
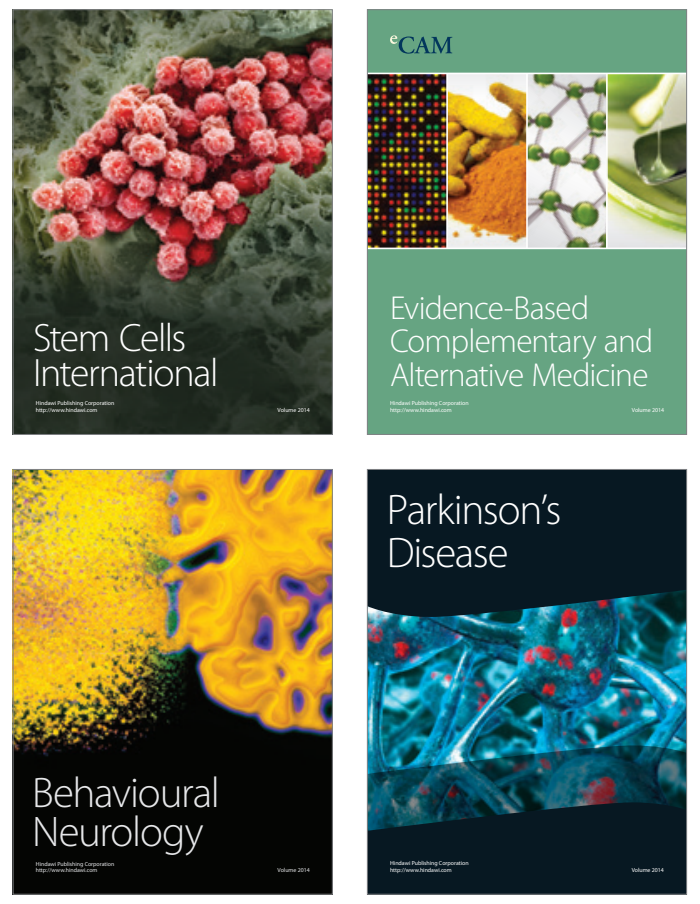
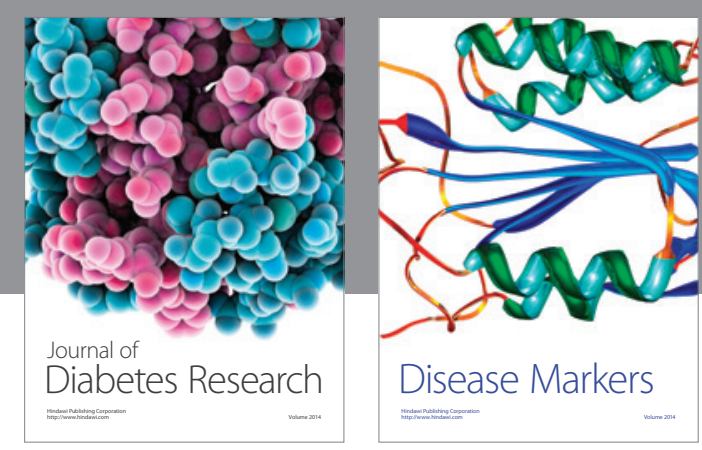

Disease Markers
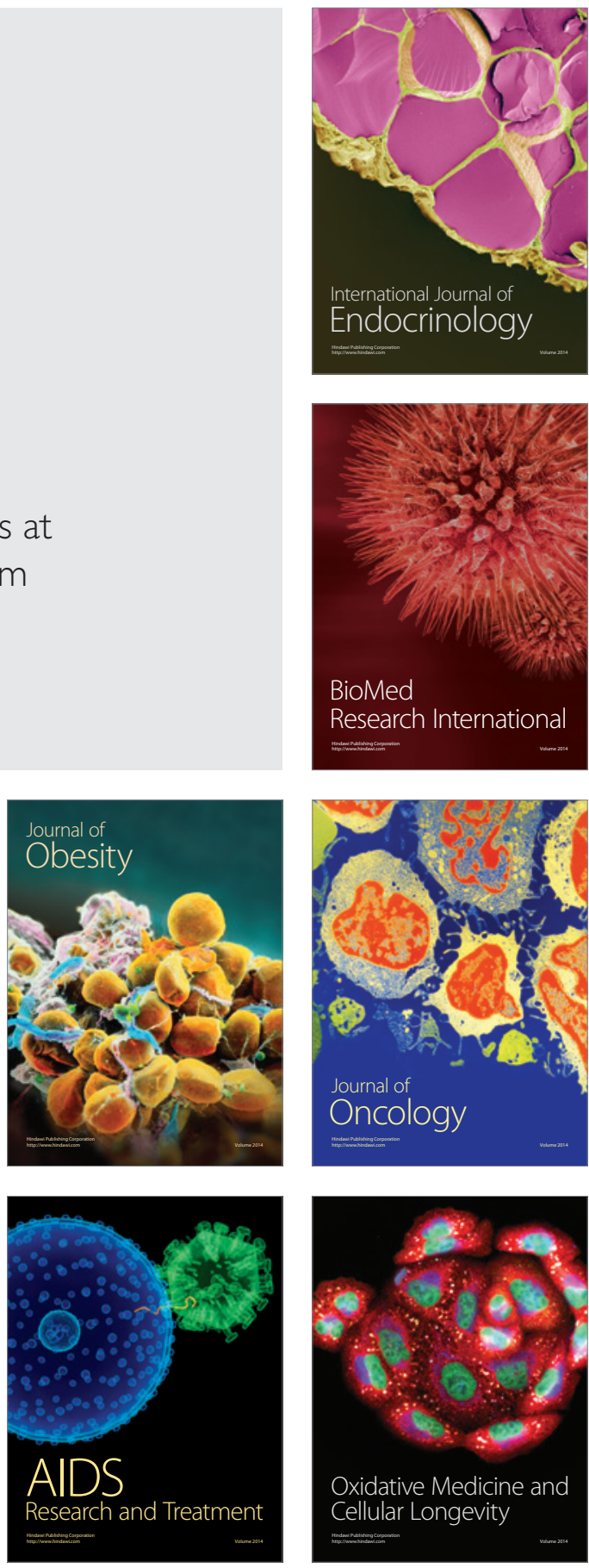